\title{
UTILITY OF SHOELACE TECHNIQUE IN CLOSURE OF FASCIOTOMY WOUNDS IN ELECTRIC BURNS
}

Dr. Praveen Kumar Arumugam ${ }^{1}$; Dr. Vamseedharan Muthukumar²; Dr. Rahul Bamal ${ }^{3}$;

Corresponding Author:

Dr. Praveen Kumar Arumugam (PKA) - MS (Gen Sur)

Dept. of Plastic, Burns \& Maxillofacial Surgery

V.M. Medical College \& Safdarjung Hospital

Delhi-110029, India

E mail: praveen.k2423@gmail.com

$\mathrm{Ph}:+919952074752$

1. Dr. Praveen Kumar Arumugam (PKA) - MS (Gen Sur)

Senior Resident, Department of Burns, Plastic \& Maxillofacial Surgery, VM Medical College \& Safdarjung hospital, Delhi. E.mail: praveen.k2423@gmail.com

Ph: +919952074752

2. Dr. Vamseedharan Muthukumar (VM) - DNB ( Gen Sur); MRCS (Ed)

Senior Resident, Department of Burns, Plastic \& Maxillofacial Surgery, VM Medical

College \& Safdarjung hospital, Delhi. E mail: drvamseedharan@gmail.com

$\mathrm{Ph}:+919543843510$

3. Dr. Rahul Bamal (RB) - MS, MRCSEd, MCh Plastic \& Reconstructive Surgery, a)Assistant Professor, Department of Burns, Plastic \& Maxillofacial Surgery, VM Medical College \& Safdarjung hospital, Delhi.

b)School of Medicine, Griffith University, Gold Coast, Australia. E mail: rahulturbo@yahoo.co.uk 
Ph: +919971102984

Place of study:

Department of Burns, Plastic \& Maxillofacial Surgery, VM Medical College \& Safdarjung hospital, Delhi.

Declarations

Conflict of interests

The authors declare that they have no conflict of interests

Funding

There was no direct or indirect funding received by authors.

Authors' contributions

RB contributed in the form of concept, design and drafting the manuscript. PKA and VM contributed by performing the procedures, collecting and analyzing data and drafting the manuscript. All authors read and approved the final manuscript. There was no writing assistance obtained.

Acknowledgements

No acknowledgement. 
ABSTRACT:

Fasciotomy is indicated to relieve compartment syndrome caused by electric burns. Many techniques are available to close the fasciotomy wounds including vacuum-assisted closure, skin grafting and healing by secondary intention. This study evaluated the shoelace technique in fasciotomy wound closure in patients of electric burns. The study included 19 fasciotomy wounds which were treated by shoelace technique (Group ST, n=10 fasciotomy wounds) or by skin grafting/healing by secondary intention (Group C, $n=9$ fasciotomy wounds). Data were collected for wound surface area, time to intervention, time to wound closure, rate of decrease in wound surface area after application of shoelace technique and associated complications.

The mean time to intervention after fasciotomy was significantly lower in Group ST - 7.6 $\underline{-} 3.8$ days as compared to $15.8 \pm 5.3$ days in Group $C(p=0.004)$. The median time to closure was also significantly lower in Group ST - 7 days (Range 6-10) as compared to Group C - 20 days (Range 12-48) $(p<0.001)$. The rate of primary closure in Group ST was $80 \%$. There were no complications noted in group ST. The shoelace technique is an economical, fast and effective method of fasciotomy wound closure in electric burns, especially in high volume centres and resource limited areas.

Keywords: Electric burns, Fasciotomy in burns, Shoelace technique, Split skin grafting, Delayed primary closure. 


\section{INTRODUCTION:}

High voltage electric burns are associated with significant morbidity and mortality. Extensive tissue damage occurs throughout the path of current depending on tissue resistance and the voltage of the current. Substantial amount of necrosis is not revealed initially as overlying skin can be normal. Up to $28 \%$ of patients with electrical contact burns can end up with limb amputations $[1,2]$. Compartment syndrome can be a limb threatening complication in these patients that is a result of increased intra-compartmental pressure that lowers the arteriovenous pressure gradient, resulting in decreased local blood flow [3]. Muscle and nerve ischemia or even necrosis can occur as a result of the insult and early fasciotomy in electrical burns has been shown to reduce amputation rates [4]. Fasciotomy wounds in electrical burns often need repeated evaluations and addressal as tissue damage is not obvious in the first instance and tissue edema tends to settle over time. They are frequently either left open to heal by secondary intention or provided skin cover in form of delayed graft or flap, timing of which is variable and depends on condition of the patient, wound environment and logistics. Delayed primary wound closure also known as third intention healing happens when the wound is intentionally left open for four to five days until edema settles and no signs of infection are seen following which the wound is closed primarily. It is associated with decreased chances of complications associated with exposed wounds like infections and provides better cosmetic outcome as compared to secondary intention healing, skin grafts and flaps, without donor site complications $[5,6]$.

There exists a considerable variability in the fasciotomy closure techniques depending on the preference of surgeon and clinical requirement of the patients in the absence of established guidelines for these wounds $[5,7,8]$. Techniques commonly used for closure include vacuum assisted closure, split skin grafting and healing by secondary intention. Shoelace technique performed after the initial fasciotomy allows gradual re-approximation of the skin edges over the course of 5 to 10 days [9]. It takes advantage of the mechanical creep due to skin elasticity. Shoelace technique has 
been used for fasciotomy wound closure in trauma patients and has been shown to significantly reduce the time to primary closure with significant reduction in length of hospital stay and very low complication rates [10]. Significant morbidity, pain at donor site and poor cosmetic results associated with skin grafting can be overcome to a great extent with shoelace technique [10]. Valuable operating time and resources can be saved as it can be done as a bedside procedure while also avoiding delay to wound closure. To the best of our knowledge, there are no studies evaluating the role of shoelace technique for fasciotomy wound closure in patients with electric burns.

\section{MATERIAL AND METHODS:}

This prospective case control study was conducted in the Department of Burns, Plastic and Maxillofacial surgery, VM Medical College \& Safdarjung Hospital, New Delhi which is a tertiary care centre and admits 350 to 400 electrical burns every year. 30 - 35 percent of our patients require a fasciotomy. Patients with electric burns who underwent fasciotomy of upper limbs to treat acute compartment syndrome, having burn surface area upto $40 \%$ of total body surface area and healthy fasciotomy wound skin margins were included in the study. Healthy wound margins are a requirement for application of staples in the shoelace technique and wounds where part of the wound had healthy margins were also included but only for corresponding wound area. Patients with poor general condition such as cardiac, renal or respiratory complications or with associated trauma like head/abdominal injury were excluded from the study. Patients fulfilling the inclusion criteria and who provided consent were included in the study. Patients randomly assigned to undergo shoelace technique based on logistics and patient consent were included as cases (Group ST) while rest of the patients were treated as controls (Group C). Controls were managed by split skin grafting or healing by secondary intention. Primary outcome was time taken for wound closure. Secondary outcome was the rate of decrease in area of wound when shoelace technique was applied. Institute Ethical Committee (IEC) approval was taken for the study. Fasciotomies were 
done using single incision flexor compartment decompression in forearm extending to the arm when necessary.

A total of 15 patients were enrolled in the study with a total of 19 fasciotomy wounds which were treated by either the shoelace technique in the interventional group (Group ST, n= 8, with 10 fasciotomy wounds) or by split skin grafting or healing by secondary intention in the control group (Group C, $n=7$, with 9 fasciotomy wounds). In cases where there was an electric contact site (example- at the wrist) with devitalized tissue (Fig 1A), the healthy part of the fasciotomy wound over the forearm was taken into consideration for both Group ST and Group C and time to closure was calculated for this area with healthy skin margins. These type of wounds with devitalized areas also required flap coverage (Fig 1E).

Technique:

All fasciotomy wounds were dressed using non-adherent dressings as per standard practice in the department. In group ST (interventional group), shoelace technique was applied once edema subsided and the viability of underlying structures was ensured. Staples were applied 2-3mm from wound margins and separated by $2 \mathrm{~cm}$ each (Fig 1B). Non-adherent gauze was applied over the wound. Standard vessel loop (Fig 1B) was laced through the staples for dermatotraction. The nonadherent dressing layer helped prevent the vessel loop cutting through the underlying soft tissue. Tightening was done every 48-72 hours, and the non-adherent dressing changed at every tightening [11]. This was done until primary wound closure (Fig 1,2) or until it was deemed ineffective by the surgeon. In group C, fasciotomy wounds were treated by split skin grafting once wound bed was healthy for graft take or were allowed to heal by secondary intention depending on theatre availabilty, wound status and patient's condition (Fig 3). Outcome of Group C (control group) patients was only observed and not influenced due to inclusion in study. Their mangement was done as per routine department practice. Wound length, breadth and area at baseline and after each tightening was measured using a free market digital application - Imitomeasure ${ }^{\mathrm{TM}}$ for android 
platform. Imitomeasure was standardized by testing with 10 different shapes with known surface areas. Ten different shapes with known surface area were printed. They were measured using the Imitomeasure app. The resultant values were compared to the original surface areas and were found to be accurate (Percent error $<0.3 \%$ ) (Table 1, Fig 4).

Statistical analysis:

Data analysis was done using SPSS software version 23. Kolmogorov-Smirnov test was applied to all quantitative variables to determine their normality. These values were then expressed as means and standard deviation or median and range. Differences in parametric and non parametric variables were tested using student's $T$ test and Mann-Whitney $U$ test respectively. The correlation between wound surface area and time to closure was analyzed using Pearson correlation coefficient. A p value of less than 0.05 was considered statistically significant.

RESULTS:

Patient characteristics of cases (interventional group) and controls have been elaborated in Table 2 . The mean age of group ST was $29.25 \pm 13.8$ years and mean age of group $C$ was $28.20 \pm 11.15$ years with no statistical difference between the two groups. All of the patients in the study were male. The median total surface area burned was $17.5 \%$ in the ST group and $10 \%$ in group C $(p=.122)$. All fasciotomies were done in upper limbs to treat acute compartment syndromes that were diagnosed clinically. A total of 19 fasciotomies were done in study subjects (Group ST, forearm9, forearm+arm-1; Group C, forearm-8, forearm+arm-1). The mean area of fasciotomy wounds at baseline in Group ST was $83.45+45.21 \mathrm{~cm}^{2}$ and the mean area in Group C was $84.12 \pm 38.15 \mathrm{~cm}^{2}$. There was no significant difference in the baseline surface area between the 2 groups.

Primary wound closure was achieved in 8 fasciotomy wounds in Group ST as two patients (2 fasciotomy wounds) required wound debridement of other areas and hence the fasciotomy wound was also grafted considering logistics of operating room availability. These 2 patients have not been 
included while comparing the two groups for 'time to wound closure'. The details of the 8 fasciotomy wounds of group ST where primary wound closure was obtained is presented in Table 3. The average reduction in wound surface area from baseline after the $1^{\text {st }}, 2^{\text {nd }}, 3^{\text {rd }}$ and $4^{\text {th }}$ tightening was $65.14 \%, 91.02 \%, 95.52 \%$ and $100 \%$ respectively. Six wounds could be closed primarily by the second tightening. Of the remaining 2 wounds, one was closed at the $3^{\text {rd }}$ tightening and one was closed at the $4^{\text {th }}$ tightening.

The two wounds in which primary closure was not obtained, the average reduction in wound surface area after the first and second tightening was $40.39 \%$ and $70.72 \%$ respectively (Table 4 ).

Four of the fasciotomy wounds healed by secondary intention and 5 wounds were managed with split skin grafting in patients of Group C. Table 5 shows the details of the individual wound surface area and time to wound closure of these wounds.

Outcomes have been summarised in Table 6. The time to intervention after fasciotomy was significantly lower in group ST $7.6 \pm 3.8$ days as compared to $15.8 \pm 5.3$ days in group $C(p=0.004)$. The shoelace technique was applied as early as 3 days in two wounds, in other patients it took longer for edema resolution and ensuring viability.

Primary closure by the shoelace technique was achieved in 8 out of the 10 wounds (80\%) but closure was achieved in $100 \%$ of patients who followed tightening schedule to the endpoint as 2 patients were taken off the schedule due to reasons not related to technique. The median time to primary closure in group ST was 7 days (Range 6-10) with average number of tightening being 2.3. Average day of split skin grafting in the 2 patients from Group ST who underwent surgical intervention before achieving primary closure was 13.5 days from the day of fasciotomy. The average reduction in surface area of fasciotomy wound in these 2 patients was $70.72 \%$ with an average number of tightening being 2 . The average time to wound closure of these 2 wounds after split skin grafting was 18.5 days. 
The median time to wound closure in group C was 20 days (Range 12-48) which was significantly higher than group ST $(p<0.001)$. The median time to wound healing by secondary intention was 42 days (Range 36-48days, $p=0.004$ ) and by split skin grafting was 15 days (Range $12-20$ days, $p=0.002$ ).

We found no significant correlation between wound surface area and time to wound closure in both groups, by using Pearson's correlation coefficient, (group ST, $r=0.097 p=0.819$; group C healing by secondary intention, $r=0.548 p=0.452$; split skin grafting, $r=0.253 p=0.681$ )

In one patient in group ST the broken vessel loop had to be changed, while in group C one patient had partial graft loss. There was no recurrence of increased compartmental pressure or necrosis of skin margins in any of the wounds during treatment.

DISCUSSION:

The shoelace technique first described by Cohn et al, 1986[11] involves the placement of staples along the wound edges, followed by threading a vessel loop through the staples like a shoelace. Since then, several variations have been studied. Nylon sutures, subcuticular $\mathrm{K}$ wires have been used instead of vessel loop $[5,12]$. This study shows the feasibility and efficacy of shoelace technique in patients with electric burns. There are no published reports in literature describing utility of the shoelace technique to the best of our knowledge (PubMed and Google Scholar searches). Ozyurtlu et al [13] used barbed sutures with gradual tightening for fasciotomy closure in 5 patients. Primary closure was observed at an average of 8.6 days in $80 \%$ of cases (4 cases out of 5). One patient had necrosis of distal edge of wound requiring removal and healing by secondary intention. We did not observe necrosis of skin margin in any of our patients. Walker et al [14], used a silicon sheet to cover the soft tissue defect and gradually re-approximated the skin margins using a running suture in patients with compartment syndrome predominantly due to a vascular etiology. They achieved a $53 \%$ closure rate with a major amputation in $23 \%$ of cases. Studies have reported $100 \%$ primary closure rates in patients with trauma related fasciotomy wounds[5]. 
We achieved an overall $80 \%$ primary closure rate in our patients while it was $100 \%$ in patients who were allowed to reach the endpoint without disruptive surgical intervention due to other reasons as mentioned above ( 2 patients). Two of the patients required debridement of other areas and hence it was decided to graft the fasciotomy wound as well in view of operating room logistics. The median duration to primary closure in our study was 7 days which was comparable to other studies in literature with a mean closure times of 6.3 to 9.8 days [10, 13-16]. Saini et al [17], performed shoelace closure of 19 fasciotomy wounds due to trauma. They were able to get closure in a mean of 3.5 tightening sessions. We observed primary closure at an average of 2.3 tightening sessions in our patients.

We found group ST to have a significantly lower time to intervention as compared to the split skin grafting group ( $7.6 \pm 3.8$ days vs $15.8 \pm 5.3$ days). The shoelace technique being a bed side procedure and not requiring operating room time may have contributed to this difference. In electrical burns the wounds in the forearm commonly require serial debridement followed by flap coverage. In the meantime, the application of shoelace helps obtain primary closure of the remaining forearm fasciotomy wound making it technically simpler to perform a flap cover.

Other methods described for fasciotomy wound closure include dynamic dermatotraction with devices like Sure Close, Silver Bullet Wound Closure Device etc. that apply progressive stretching force to skin making use of mechanical creep to achieve delayed primary closure. But a big drawback is that these devices are expensive ranging from $\$ 500$ to $\$ 1000$ [5]. Vaccum assisted closure (VAC) also helps in closure be creating a sterile environment for wound closure with negative suction pressure enabling early resolution of edema thereby hastening wound healing. Similar to dermatotraction devices, it is associated with high costs. Another disadvantage is that VAC cannot be applied directly over neurovascular structures which could be exposed as a result of fasciotomy [18]. The equipment required for VAC costs approximately US\$96.51 per day [19]. 
Comparisons have been done between the different techniques for fasciotomy wound closure. Kakajia et al [20], performed a randomised control study comparing vaccum assisted closure versus shoelace technique. Twenty-five patients with leg fasciotomies due to fractures and soft tissue injuries were included in study. Wound closure time was significantly higher in vacuum group as compared to shoelace group ( $p=0.001$ ) (6.3 vs 1.8 days). Also the cost of vacuum assisted closure was significantly higher as compared to the shoelace group. In a study by Janzing et al [21] shoelace technique was superior to dynamic dermatotraction in delayed primary closure (100\% vs $60 \%)$. Complications associated with dynamic dermatotraction were wound edge necrosis, weakness and delayed bone healing. In a meta-analysis of wound closure techniques following fasciotomy by Jauregui et al [8], the highest success rate was observed for dynamic dermatotraction (93\%) and gradual suture approximation (92\%), followed by VAC (78\%). However, VAC had the lowest complication rate $(2 \%)$, followed by gradual suture approximation $(15 \%)$, and then dynamic dermatotraction (18\%).

Advantage of shoelace technique as compared to other methods of closure include the use of relatively inexpensive materials, faster closure times with possibility of doing the procedure bedside. In a retrospective analysis by Zorilla et al [10], shoelace technique was found to avoid the use of free skin grafts to close the dermotomy-fasciotomy wounds, reducing the need for anesthesia, nursing care, and hospital stays of patients, resulting in lower healthcare costs. None of the 20 patients in whom shoelace technique was applied required surgical intervention. Disadvantages of the technique include, loosening of sutures or marginal ischemia due to point loading at the staple insertion sites by pull forces is more common in modified techniques using other materials [5]. We observed that applying the staples after reduction in edema prevented staple loosening. There was no incidence of marginal ischemia in this study.

Patients with burns are a unique group where approximation of wound edges with shoelace might be difficult in view of unhealthy/ burnt surrounding skin. However, there exists a certain 
subgroup of patients with electric contact burns undergoing fasciotomy who have healthy wound margins and will benefit from primary closure with shoelace technique. The advantage in electric burns in achieving primary closure is that it helps in planning and performing further soft tissue cover, if needed, in order to salvage the hand. Shoelace technique is a simple bedside procedure, hence there is no delay due to waiting for wound to granulate or for fitness of patient. In a high volume centre as ours, it helps achieving closure without need for operating room time. In forearm wounds requiring subsequent reconstructive procedures, primary closure can be the preferred option. Shoelace technique is also much cheaper as compared to other devices or VAC. The staples and a pair of vessel loops used for the shoelace technique cost about INR 850 (US \$11) as compared to a treatment session of VAC which is about INR 10000 (US \$130).

Limitations of the study:

Non-randomized and non-blinded nature of the study predisposes to selection bias. Sample size was small but the results are statistically significant.

Future Direction:

Larger prospective and better designed study comparing different techniques for fasciotomy closure in electrical burn patients is suggested for providing a higher level of evidence and statistical significance.

CONCLUSION:

Shoelace technique is a and faster method of fasciotomy wound closure. It makes it an effective and practical method, especially in high volume and resource limited areas managing electric burns. The shoelace technique is largely underused in spite of its advantages and our study demonstrates its utility and feasibility in electric burns. 
REFERENCES:

[1] Buja Z, Arifi H, Hoxha E. Electrical Burn Injuries. An Eight-year Review. Ann Burns Fire Disasters. 2010;23:4-7.

[2] Handschin AE, Vetter S, Jung FJ, Guggenheim M, Kunzi W, Giovanoli P. A casematched controlled study on high-voltage electrical injuries vs thermal burns. J Burn Care Res. 2009;30:400-7.

[3] McLaughlin N, Heard H, Kelham S. Acute and chronic compartment syndromes: know when to act fast. JAAPA. 2014;27:23-6. doi: 10.1097/01.JAA.0000446999.10176.13.

[4] Huei TJ, Mohd Yussof SJ, Lip HTC, Salina I. Case report of a high voltage electrical injury and review of the indications for early fasciotomy in limb salvage of an electrically injured limb. Ann Burns Fire Disasters. 2017;30(2):150-153.

[5] Kakagia D. How to Close a Limb Fasciotomy Wound: An Overview of Current Techniques. Int J Low Extrem Wounds. 2015;14:268-76, doi: 10.1177/1534734614550310.

[6] Dimick AR. Delayed wound closure: indications and techniques. Ann Emerg Med. 1988;17:1303-4. doi: $10.1016 / \mathrm{s} 0196-0644(88) 80355-x$.

[7] Bussell HR, Aufdenblatten CA, Gruenenfelder C, Altermatt S, Tharakan SJ. Comparison of lower extremity fasciotomy wound closure techniques in children: vacuum-assisted closure device versus temporary synthetic skin replacement. Eur J Trauma Emerg Surg. 2019;45:809-14. doi: 10.1007/s00068-018-0985-9.

[8] Jauregui JJ, Yarmis SJ, Tsai J, Onuoha KO, Illical E, Paulino CB. Fasciotomy closure techniques. J Orthop Surg (Hong Kong). 2017;25:2309499016684724. doi: 10.1177/2309499016684724.

[9] Berman SS, Schilling JD, McIntyre KE, Hunter GC, Bernhard VM. Shoelace technique for delayed primary closure of fasciotomies. Am J Surg. 1994;167:435-6. doi: 10.1016/0002-9610(94)90130-9. 
[10] Zorrilla P, Marin A, Gomez LA, Salido JA. Shoelace technique for gradual closure of fasciotomy wounds. J Trauma. 2005;59:1515-7. doi: 10.1097/01.ta.0000199242.24511.30

[11] Cohn BT, Shall J, Berkowitz M. Forearm fasciotomy for acute compartment syndrome: a new technique for delayed primary closure. Orthopedics. 1986;9:1243-6.

[12] Almekinders LC. Tips of the trade \#32. Gradual closure of fasciotomy wounds. Orthop Rev. 1991;20:82, 4.

[13] Ozyurtlu M, Altinkaya S, Baltu Y, Ozgenel GY. A new, simple technique for gradual primary closure of fasciotomy wounds. Ulus Travma Acil Cerrahi Derg. 2014;20:194-8. doi: 10.5505/tjtes.2014.54077.

[14] Walker T, Gruler M, Ziemer G, Bail DH. The use of a silicon sheet for gradual wound closure after fasciotomy. J Vasc Surg. 2012;55:1826-8. doi: 10.1016/j.jvs.2011.12.009.

[15] Medina C, Spears J, Mitra A. The use of an innovative device for wound closure after upper extremity fasciotomy. Hand (N Y). 2008;3:146-51. doi: 10.1007/s11552-007-9082-y

[16] Taylor RC, Reitsma BJ, Sarazin S, Bell MG. Early results using a dynamic method for delayed primary closure of fasciotomy wounds. J Am Coll Surg. 2003;197:872-8. doi: 10.1016/S10727515(03)00646-X.

[17] Saini RA, Sharma D, Shah N.Shoe lace technique, a simple and less expensive method for Fasciotomy wound closure following compartment syndrome. International Journal of Orthopaedics Sciences 2018; 4(1): 445-449 doi: https://doi.org/10.22271/ortho.2018.v4.i1g.64.

[18] Laverty D., Webb L.X. (2004) Vacuum-Assisted Closure: Orthopaedic Applications. In: Téot L., Banwell P.E., Ziegler U.E. (eds) Surgery in Wounds. Springer, Berlin, Heidelberg 
[19] Webster J, Scuffham P, Sherriff KL, Stankiewicz M, Chaboyer WP. Negative pressure wound therapy for skin grafts and surgical wounds healing by primary intention. Cochrane Database Syst Rev. 2012:CD009261. doi: 10.1002/14651858.CD009261.pub2.

[20] Kakagia D, Karadimas EJ, Drosos G, Ververidis A, Trypsiannis G, Verettas D. Wound closure of leg fasciotomy: comparison of vacuum-assisted closure versus shoelace technique. A randomised study. Injury. 2014;45:890-3. doi: 10.1016/j.injury.2012.02.002.

[21] Janzing HM, Broos PL. Dermatotraction: an effective technique for the closure of fasciotomy wounds: a preliminary report of fifteen patients. J Orthop Trauma. 2001;15:438-41. doi: $10.1097 / 00005131-200108000-00010$ 


\section{FIGURE LEGEND:}

Fig1. Case 1. A- Fasciotomy wound, showing devitalized tissue at wrist. B- Shoelace technique: staples placed at margin of the wound, vessel loops passed through staples alternatively. C- Day 2 post application. D- Wound closed on day 6 . E- Follow up at 3 months showing well healed scar and flap used for the wrist wound.

Fig2. Case 2. A- Fasciotomy wound. B- Shoelace technique applied. C- Day 2 post application. DWound closed on day 4

Fig3. Controls. A- Fasciotomy wound healed by secondary intention. B- Fasciotomy wound managed with split skin grafting.

Fig4. Measurement of an arc by Imitomeasure app. 


\section{TABLES}

Table 1. Standardisation of Imitomeasure app using shapes of known areas.

\begin{tabular}{|c|c|c|c|}
\hline Shape & $\begin{array}{l}\text { Actual surface area } \\
\left(\mathrm{cm}^{2)}\right.\end{array}$ & $\begin{array}{l}\text { Surface area as } \\
\text { measured by } \\
\text { Imitomeasure }\left(\mathrm{cm}^{2)}\right.\end{array}$ & Percent Error \\
\hline Triangle & 83.14 & 83.39 & 0.30 \\
\hline Square & 128 & 128.2 & 0.15 \\
\hline Pentagon & 152.17 & 152.31 & 0.09 \\
\hline Hexagon & 166.28 & 166.42 & 0.08 \\
\hline Heptagon & 175.13 & 175.26 & 0.07 \\
\hline Octagon & 181.02 & 181.5 & 0.26 \\
\hline Nonagon & 185.12 & 184.93 & -0.10 \\
\hline Circle & 113.1 & 113.23 & 0.11 \\
\hline Ellipse & 194.15 & 194.2 & 0.02 \\
\hline Arc & 100.64 & 100.92 & 0.27 \\
\hline
\end{tabular}


Table 2. Characteristics of patients in Group ST and Group C.

\begin{tabular}{|c|c|c|c|}
\hline Characteristic & $\begin{array}{l}\text { Group ST (interventional } \\
\text { group) }\end{array}$ & Group C (control group) & P value \\
\hline Total no. of patients & 8 & 7 & \\
\hline Total no. of fasciotomy wounds & 10 & $\begin{array}{l}9 \\
\text { Secondary intention - } 4 \\
\text { Split skin grafting - } 5\end{array}$ & \\
\hline$M: F$ & $8: 0$ & $7: 0$ & \\
\hline Mean age (years) & $29.25 \pm 13.80$ & $28.20 \pm 11.15$ & 0.307 \\
\hline $\begin{array}{l}\text { Median area of electric burns } \\
\text { in terms of } \% \text { TBSA }\end{array}$ & $17.5 \%(5-35 \%)$ & $10 \%(10-20 \%)$ & 0.122 \\
\hline $\begin{array}{l}\text { Site of fasciotomy: } \\
\text { Forearm } \\
\text { Forearm + arm }\end{array}$ & $\begin{array}{l}9 \\
1\end{array}$ & $\begin{array}{l}8 \\
1\end{array}$ & \\
\hline $\begin{array}{l}\text { Mean surface area of wound at } \\
\text { baseline }\left(\mathrm{cm}^{2}\right)\end{array}$ & $83.45 \pm 45.21$ & $84.12 \pm 38.15$ & 0.973 \\
\hline
\end{tabular}

No.: Number, M: Male, F: Female, TBSA: Total Body Surface Area 
Table 3. Group ST - Surface area reduction for cases where primary wound closure was obtained.

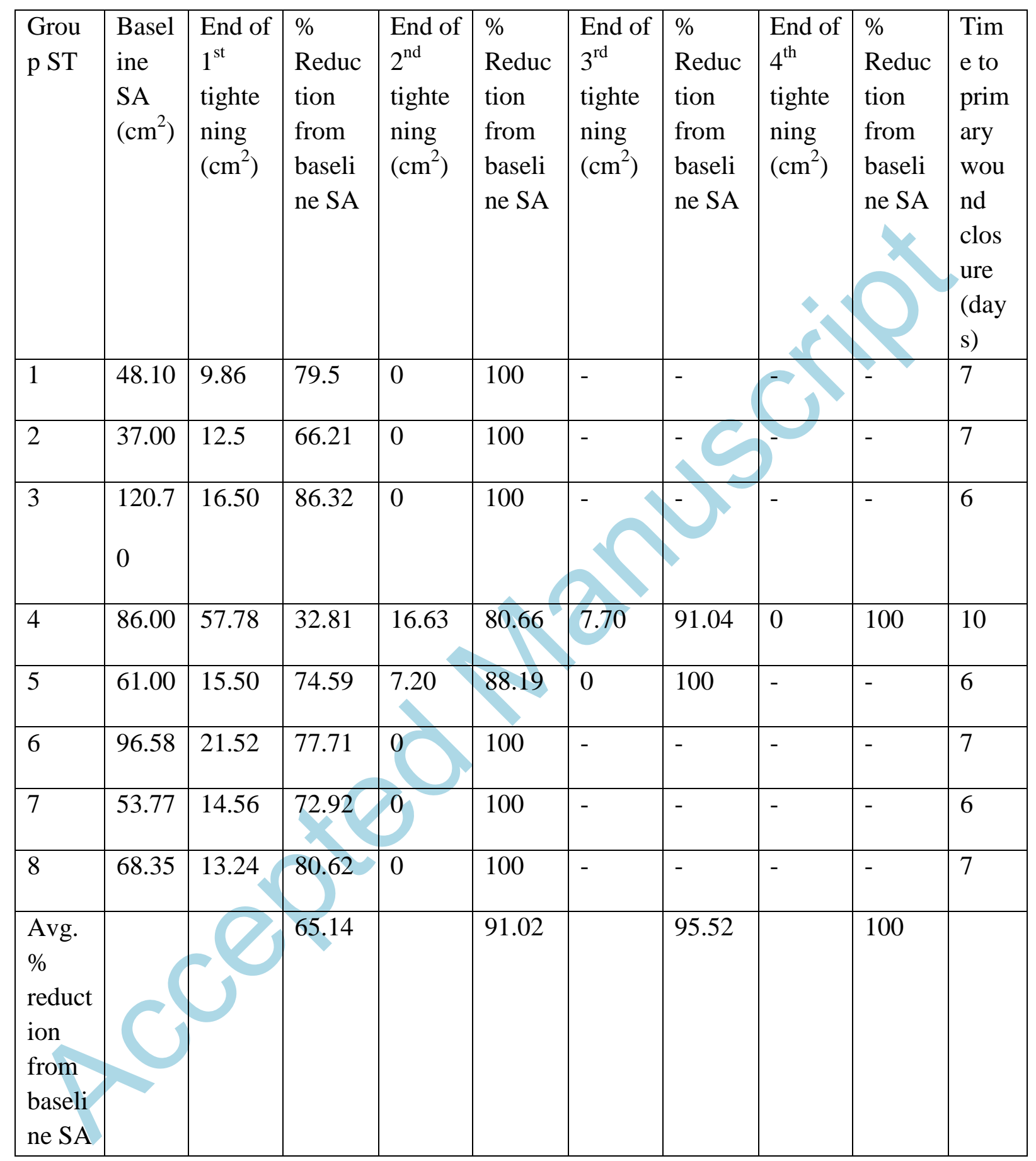

SA - Surface area 
Table 4. Group ST - Surface area reduction for cases where primary wound closure was not obtained (intervention occurred before reaching the endpoint)

\begin{tabular}{|l|l|l|l|l|l|}
\hline Group ST & $\begin{array}{l}\text { Baseline SA } \\
\left(\mathrm{cm}^{2}\right)\end{array}$ & $\begin{array}{l}\text { End of } 1^{\text {st }} \\
\text { tightening } \\
\left(\mathrm{cm}^{2}\right)\end{array}$ & $\begin{array}{l}\text { \% Reduction } \\
\text { from } \\
\text { baseline SA }\end{array}$ & $\begin{array}{l}\text { End of 2 } \\
\text { tightening } \\
\left(\mathrm{cm}^{2}\right)\end{array}$ & $\begin{array}{l}\text { \% Reduction } \\
\text { from baseline } \\
\text { SA }\end{array}$ \\
\hline 1 & 192.00 & 122.26 & 36.32 & 57.50 & 70.05 \\
\hline 2 & 94.40 & 52.42 & 44.47 & 27.00 & 71.39 \\
\hline $\begin{array}{l}\text { Avg. \% } \\
\text { reduction } \\
\text { from } \\
\text { baseline SA }\end{array}$ & & & 40.39 & & 70.72 \\
\hline
\end{tabular}

SA - Surface area 
Table 5. Group C - Baseline surface area and time to wound closure.

\begin{tabular}{|l|l|l|}
\hline Group C & Baseline SA $\left(\mathrm{cm}^{2}\right)$ & Time to wound closure (days) \\
\hline \multicolumn{2}{|l|}{ Healing by secondary intention } \\
\hline 1 & 112.00 & 48 \\
\hline 2 & 98.00 & 36 \\
\hline 3 & 92.30 & 46 \\
\hline 4 & 88.00 & 38 \\
\hline Split Skin Grafting & \multicolumn{2}{|l|}{} \\
\hline 1 & 82.30 & 12 \\
\hline 2 & 32.10 & 13 \\
\hline 3 & 49.50 & 15 \\
\hline 4 & 46.30 & 20 \\
\hline 5 & 156.60 & 18 \\
\hline
\end{tabular}

SA - Surface area 
Table 6. Analysis of outcome

\begin{tabular}{|c|c|c|c|}
\hline & Group ST (cases) & Group C (controls) & P value \\
\hline $\begin{array}{l}\text { Time to intervention } \\
\text { after fasciotomy }\end{array}$ & $\begin{array}{l}\text { Application of shoelace } \\
7.6 \pm 3.8 \text { days }\end{array}$ & $\begin{array}{l}\text { Split skin grafting } \\
15.8 \pm 5.3 \text { days }\end{array}$ & 0.004 \\
\hline $\begin{array}{l}\text { Median time to wound } \\
\text { closure }\end{array}$ & 7 days (Range 6-10) & $\begin{array}{l}20 \text { days (Range 12-48) } \\
\text { Healing by secondary } \\
\text { intention: } 42 \text { days (Range } 36- \\
48 \text { ) } \\
\text { Split Skin Grafting: } 15 \text { days } \\
\text { (Range } 12-20)\end{array}$ & $\begin{array}{l}<0.001 \\
0.004\end{array}$ \\
\hline $\begin{array}{l}\text { Correlation between } \\
\text { wound surface area and } \\
\text { time to wound closure }\end{array}$ & $\begin{array}{l}\mathrm{r}^{*}=0.097 \\
\mathrm{p}^{* *}=0.819\end{array}$ & $\begin{array}{l}\text { Healing by secondary } \\
\text { intention: } \\
r=0.548 \\
p=0.452 \\
\text { Split Skin Grafting: } \\
r=0.253 \\
p=0.681\end{array}$ & \\
\hline
\end{tabular}

${ }^{*}$ Pearsons correlation coefficient, $r$.

${ }^{* *}$ Corresponding $\mathrm{p}$ value 
Figure 1

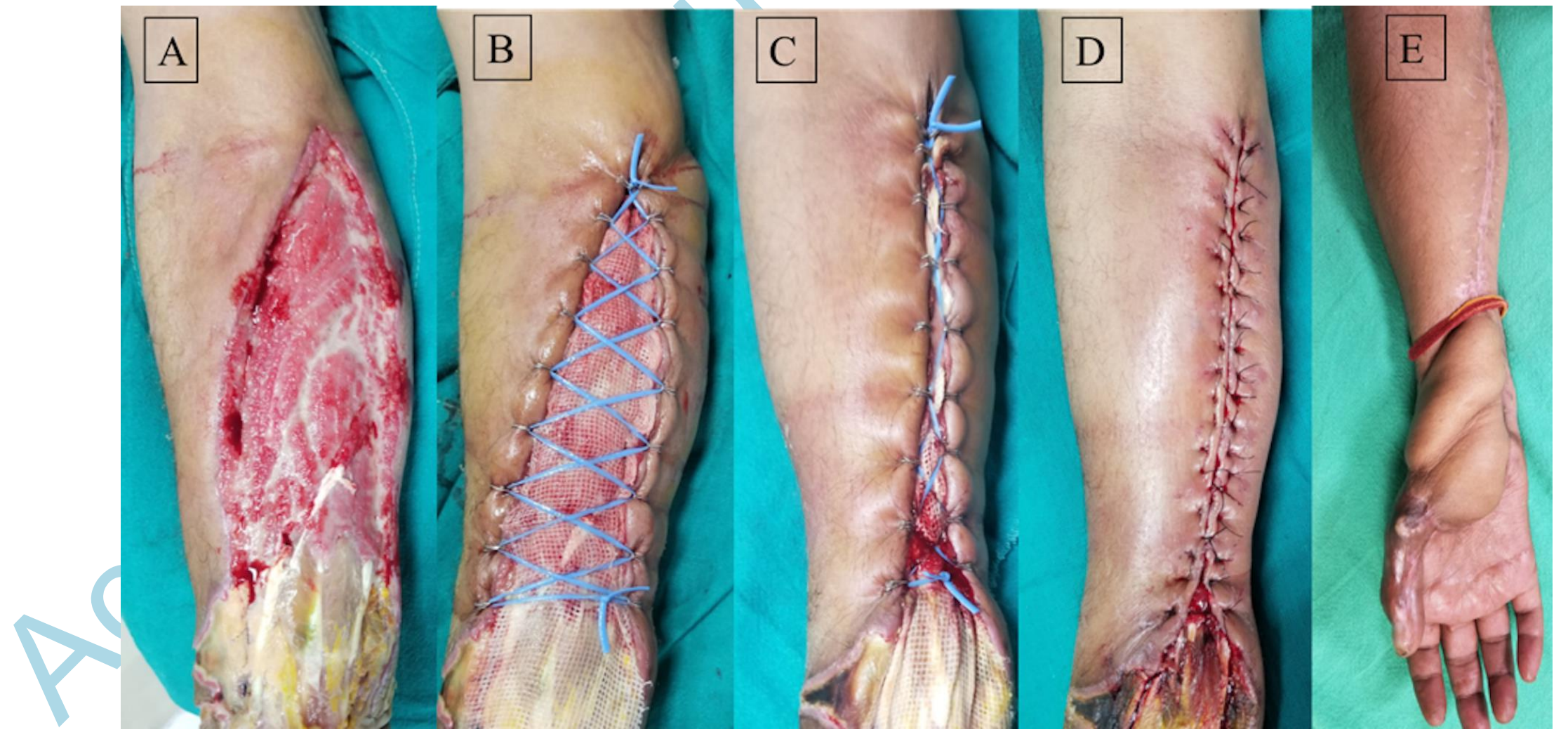


Figure 2

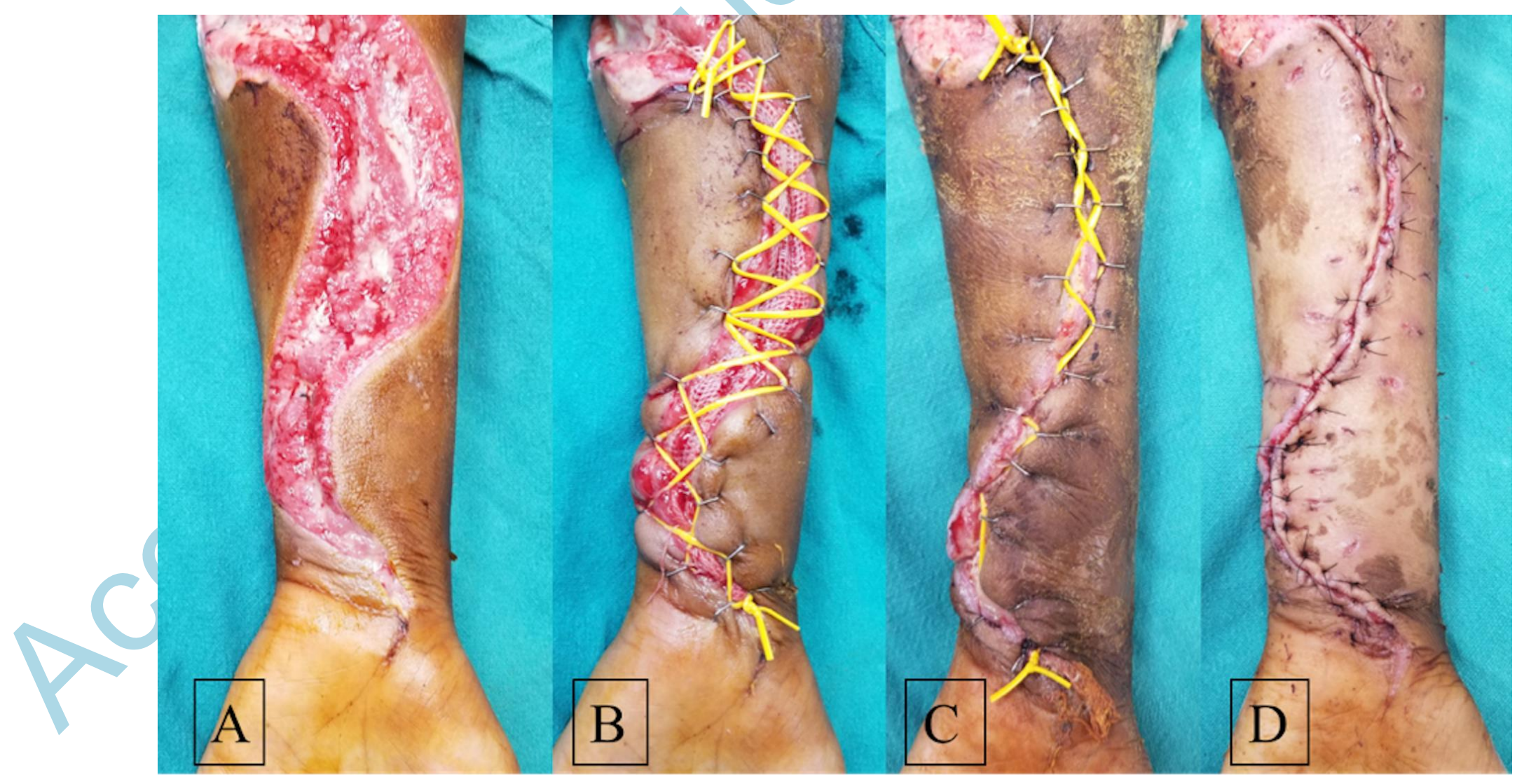


Figure 3

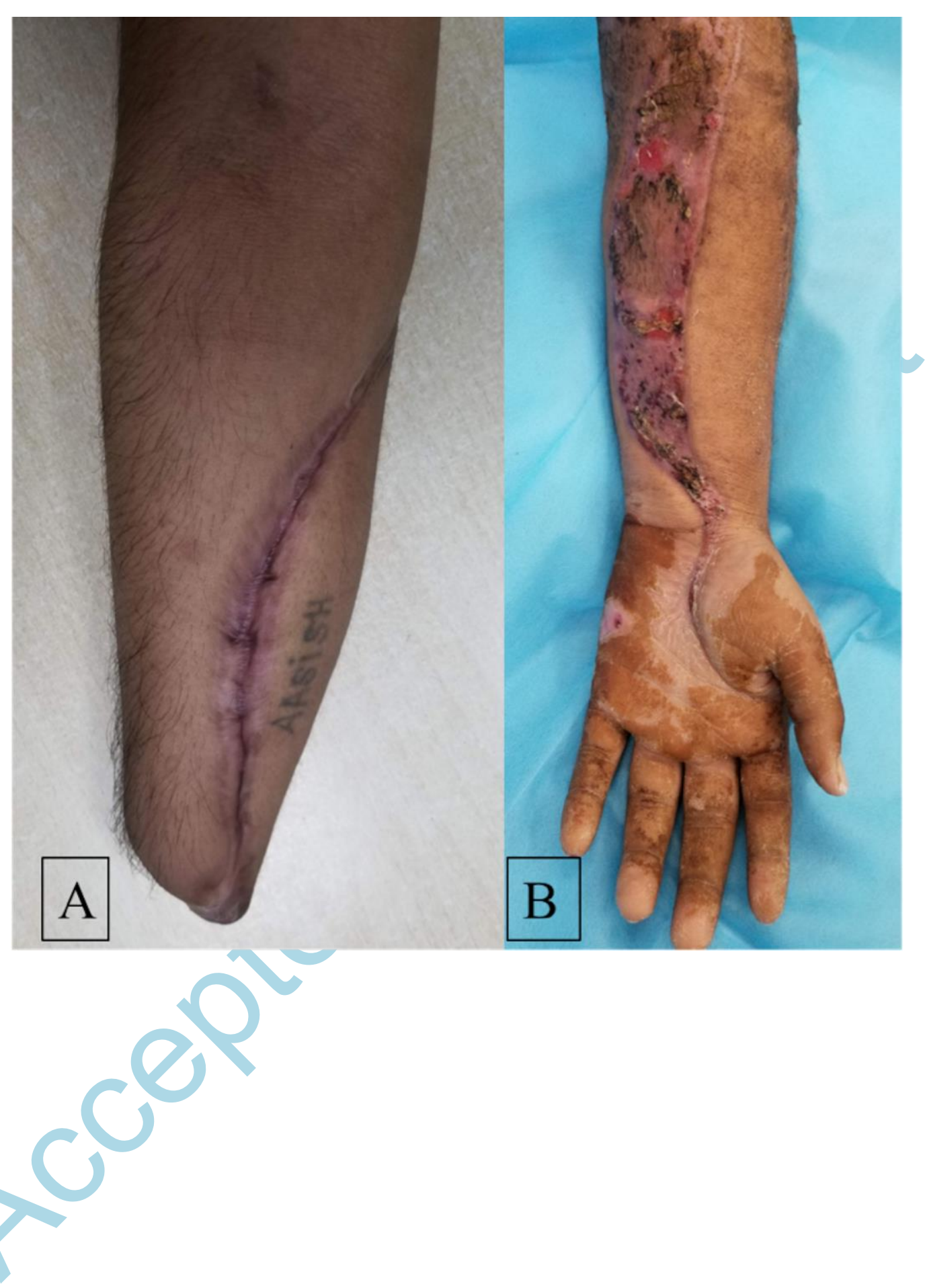




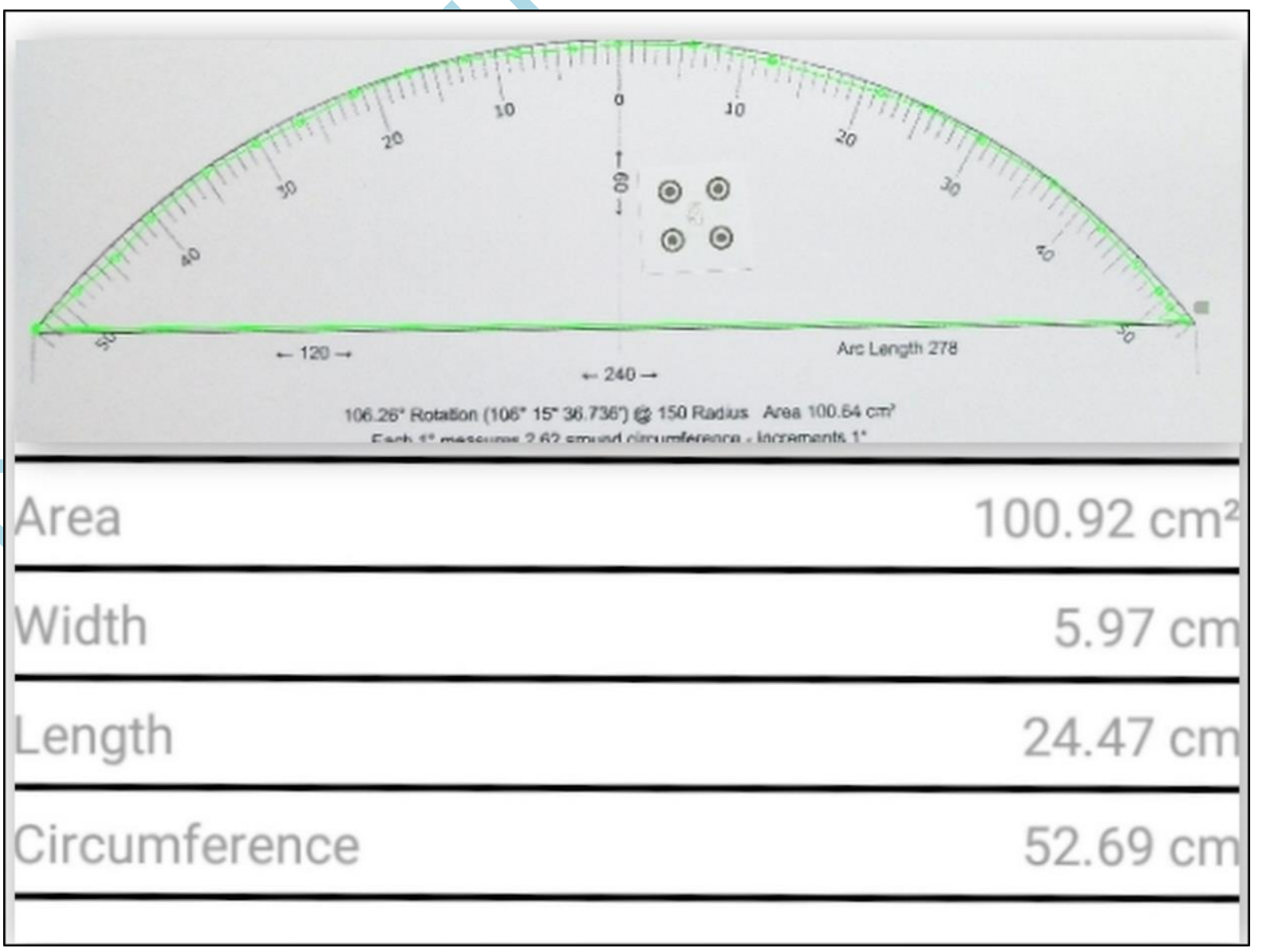

